\title{
Syncronous medullar thyroid cancer and primary hyperparathyroidism on a female within the sixth decade of life with positive family history for type $2 A$ MEN syndrome
}

\author{
Ana VALEA ${ }^{1}$, Otilia RADU ${ }^{2}$, Andra MORAR ${ }^{3}$, Adina GHEMIGIAN ${ }^{2,4}$, Mara CARSOTE ${ }^{2,4}$ \\ ${ }^{1}$ Clinical County Hospital, "I. Hatieganu” University of Medicine and Pharmacy, Cluj-Napoca \\ 2"Carol Davila" University of Medicine and Pharmacy, Bucharest \\ ${ }^{3}$ Clinical Hospital of Infectious Diseases, Cluj-Napoca \\ 4"C.I. Parhon" National Institute of Endocrinology, Bucharest
}

\begin{abstract}
Medullar thyroid cancer (MTC) may be sporadic or familial, either linked with pheocromocy toma (PHEO) and primary hyperparathyrodism (PHP), as seen in type $2 \mathrm{~A}$ MEN (Multiple Endocrine Neoplasia) syndrome, either isolated.

This is a 56-year old female known with mild arterial hypertension controlled under therapy, having a daughter with type $2 A$ MEN syndrome (PHEO, MTC, PHP). Mild hypercalcemia and high parathormone were consistent for PHP, while calcitonin was 20 times above the upper normal limit for MTC. The PHEO tests were negative. Anterior cervical ultrasound confirmed a $2.7 \mathrm{~cm}$ thyroid nodule, local lymph nodes, and enlargement of inferior and superior left prarathyroids. After total thyroidectomy with bilateral neck dissection and excision of the left inferior and superior parathyroid glands, MTC and parathyroid hyperplasia was confirmed. Calcitonin decreased to 5 times above the normal level. Further close follow-up and therapy of residual MTC is needed.

MEN 2A Syndrome may embrace various clinical presentations with more or less aggressive tumours, sometimes allowing a long time survival without neoplasia confirmation or incomplete phenotype until advanced age.
\end{abstract}

Keywords: medullar thyroid cancer, primary hyperparathyroidism, MEN syndrome

\section{LIST OF ABBREVIATIONS}

$\mathrm{mm}=$ millimetre; $\mathrm{ACE}=$ angiotensin-converting-enzyme; DXA = Dual-Energy X-Ray Absorptiometry; FT4 = free levothyroxine; $\mathrm{MTC}=$ Medullar Thyroid Cancer; MEN = Multiple Endocrine Neoplasia; $\mathrm{PHEO}=$ pheocromocytoma; $\mathrm{PHP}=$ primaty hyperparathyroidism; $\mathrm{PTH}=$ parathyroid hormone; RET = REarranged during Transfection; TSH = Thyroid Stimulating Hormone; TPO = antithyreoperoxidase antibodies; US = ultrasound

\section{INTRODUCTION}

Medullar thyroid cancer (MTC) may be sporadic or familial, either linked with pheocromocytoma (PHEO) and primary hyperparathyrodism (PHP) as seen in type 2A MEN (Multiple Endocrine Neoplasia) syndrome, or isolated $(1,2)$. Once the RET (REarranged during Transfection) mutation is positive, there is a time-dependent pattern of tumours' onset, knowing that phenotype and age at diagnosis are tidily connected with the mutation itself $(2,3,4)$. MTC

\section{Correspondence:}

Mara Carsote MD, PhD, “C.I. Parhon” National Institute of Endocrinology, 34-38 Aviatorilor Ave, District 1, Bucharest, Romania E-mail: carsote_m@hotmail.com 
and then PHEO are the most frequent neoplasia in MEN 2A syndrome, opposite to $\operatorname{PHP}(3,4)$. We aim to introduce an adult female case having a late recognition of the syndrome despite relevant family history and displaying a particular clinical presentation with positive HPT before PHEO confirmation.

\section{CASE PRESENTATION}

We report the case of a 56-year old non-smoking female who was admitted in the Department of Endocrinology in March 2016 for polyuria, polydipsia and intermittent headache. The patient had a history of grade I arterial hypertension, adequately controlled with ACE (angiotensin-converting-enzyme) inhibitors. The patient's daughter had been diagnosed with type 2A MEN syndrome based on PHEO, MTC plus PHP (no RET test was available, though).

On admission, the physical exam revealed grade I obesity, heart rate of 68 beats per minute, blood pressure $110 / 70 \mathrm{mmHg}$, without orthostatic hypotension. Laboratory tests found mild hypercalcemia and elevation of alkaline phosphatase levels (Table 1). The hormonal profile revealed high PTH (parathyroid hormone) consistent for PHP and extremely high circulating calcitonin levels (20 times above the upper normal limit), suggestive for MTC (Table 1). In association with family medical history, these data raised the question of a MEN 2A syndrome, so the adrenal tests seeking for PHEO were done (including chromogranin A, 24-hour urinary metanephrines and normetanephrines) (Table 1). No hormonal or imagery clue of the adrenal tumour was found.

Thyroid ultrasound (US) found multi-nodular goitre, a deeply hypoechoic nodule located in the left lobe, with irregular margins, predominantly peri-nodular vascularisation and intra-nodular coarse calcifications, measuring 17.7 by 18.9 by $27.5 \mathrm{~mm}$ (millimetre) (Figure 1). In addition, anterior cervical US described a left cervical lymph node of 9.9 by $11.2 \mathrm{~mm}$ in diameter, and two extra-capsular nodules of 14.8 by $10.8 \mathrm{~mm}, 11.6$ by $7.6 \mathrm{~mm}$ respectively, possibly left inferior and left superior parathyroid glands and associated adenoma. Contrast-enhanced computer tomography scans of the neck, chest, abdomen and pelvis revealed a thyroid nodule of 20 by 18 by $20 \mathrm{~mm}$ with lymph nodes enlargement by the same side and, also, another nodule of $11 \mathrm{~mm}$ maximum diameter, located at the posterior part of the left thyroid lobe,
TABLE 1. The panel of investigations consistent with Medullar Thyroid Cancer and Primary Hyperparathyroidism on a 56-year old female having positive family history for type $2 A$ MEN Syndrome. The data are displayed at first diagnosis and three months after cervical surgery which provided the pathological confirmation of both conditions.

\begin{tabular}{|c|c|c|c|}
\hline Parameter & Value & $\begin{array}{l}\text { Normal } \\
\text { value }\end{array}$ & Units \\
\hline \multicolumn{4}{|c|}{ At diagnosis } \\
\hline Calcitonin & 2000 & $<10$ & $\mathrm{pg} / \mathrm{ml}$ \\
\hline TSH & 0.54 & $0.4-4$ & $\mu \mathrm{IU} / \mathrm{mL}$ \\
\hline FT4 & 1.59 & $0.89-1.76$ & $\mathrm{ng} / \mathrm{dl}$ \\
\hline TPO & 18.2 & $<50$ & $\mathrm{Ul} / \mathrm{ml}$ \\
\hline PTH & 126.5 & $11-67$ & $\mathrm{pg} / \mathrm{ml}$ \\
\hline Total serum calcium & 10.78 & 8.8-10.6 & $\mathrm{mg} / \mathrm{dl}$ \\
\hline Ionized serum calcium & 4.57 & $4.4-5.4$ & $\mathrm{mg} / \mathrm{dl}$ \\
\hline Serum phosphorus & 2.64 & $2.5-4.5$ & $\mathrm{mg} / \mathrm{dl}$ \\
\hline Serum creatinine & 0.58 & $0.51-0.95$ & $\mathrm{mg} / \mathrm{dl}$ \\
\hline Serum alkaline phosphatase & 140 & $30-120$ & $\mathrm{U} / \mathrm{I}$ \\
\hline $\begin{array}{l}\text { 24-hours urinary } \\
\text { metanephrines }\end{array}$ & 86.8 & $<375$ & $\mu \mathrm{g} / 24 \mathrm{~h}$ \\
\hline $\begin{array}{l}\text { 24-hours urinary } \\
\text { normetanephrines }\end{array}$ & 148 & $<632$ & $\mu g / 24 \mathrm{~h}$ \\
\hline Blood chromogranin A & 34.06 & $<76.3$ & $\mathrm{ng} / \mathrm{ml}$ \\
\hline \multicolumn{4}{|c|}{$\begin{array}{c}\text { Three months after total thyroidectomy and } \\
\text { parathyroidectomy }\end{array}$} \\
\hline Calcitonin & 112.4 & $<10$ & $\mathrm{pg} / \mathrm{ml}$ \\
\hline TSH & $31.4 *$ & $0.4-4$ & $\mu \mathrm{IU} / \mathrm{mL}$ \\
\hline FT4 & $0.95 *$ & $0.89-1.76$ & $\mathrm{ng} / \mathrm{dl}$ \\
\hline PTH & 26.3 & $11-67$ & $\mathrm{pg} / \mathrm{ml}$ \\
\hline Total serum calcium & 8.42 & 8.8-10.6 & $\mathrm{mg} / \mathrm{dl}$ \\
\hline Ionized serum calcium & 3.67 & 4.4-5.4 & $\mathrm{mg} / \mathrm{dl}$ \\
\hline Serum alkaline phosphatase & 101 & $30-120$ & $\mathrm{U} / \mathrm{I}$ \\
\hline \multicolumn{4}{|c|}{$\begin{array}{l}\text { TSH=Thyroid Stimulating Hormone; FT4=Free } \\
\text { Levothyroxine; TPO=anti-thyreoperoxidase antibodies; } \\
\text { PTH=parathyroid hormone }\end{array}$} \\
\hline
\end{tabular}

suggestive for a parathyroid adenoma. No other lesions of the liver, lungs or adrenal glands were detected. Central DXA (Dual-Energy X-Ray Absorptiometry) scan revealed osteoporosis (in correlation with menopausal status and PHP).

In April 2016, the patient underwent total thyroidectomy with bilateral neck dissection and excision of the left inferior and superior parathyroid glands. The pathological report confirmed MTC and double parathyroid hyperplasia lesions. Three months after surgery, blood calcitonin decreased, but remained elevated despite no evidence of loco-regional disease on US. The patient presented with mild hypocalcemia with normal PTH, requiring an increase in calcium and vitamin D supplementation, as well as high TSH (Thyroid Stimulating Hormone) 


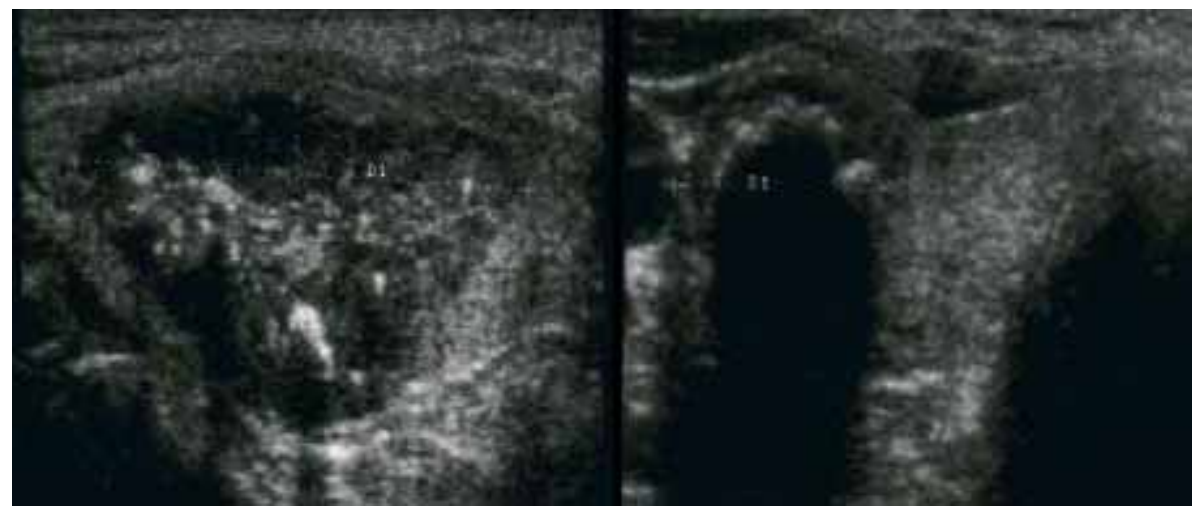

FIGURE 1. Preoperative anterior cervical ultrasound scan (different windows) of a 56-yearold patient with MEN 2A syndrome suggestive for an aggressive thyroid condition (confirmed as medullar thyroid cancer)

that required levothyroxine dose adjustments (Table 1). Further close follow-up and identification of residual MTC with adequate therapy is needed, as well as periodical check up for PHEO.

\section{DISCUSSION}

This case highlights a daily practice endocrine experience in a family with RET mutation (without the exact mutation on the proto-oncogene identified yet, but the clinical configuration is extremely suggestive). Type 2A MEN syndrome involves repeated surgeries and life-long follow-up (5-7). The presented case associates an atypical late diagnosis within the sixth decade of life $(8,9)$. The history of high arterial blood pressure was not consistent with PHEO up this moment, despite high frequency of the adrenal neoplasia in family with RET mutations and the fact that the patient's daughter had already been confirmed with PHEO (8). The headache the female accused was related to the blood pressure control, while the polyuria-polydipsia syndrome was associated with hypercalcemia. The phenotype was milder than seen at her younger relative, noting the fact that sydromic genotype-phenotype correlation vary $(6,9)$. We were not able to provide the entire pedigree consistent with tumours presence over the time in the family, despite its importance. We consider the most important clue of this case the lack of PHEO up to the age of 56 years (while PHP is already confirmed) which, apart from bilateral aspects in most cases, is expected to a $100 \%$ penetrance for some RET codons mutations (10). Unfortunately, after total thyroidectomy and careful bilateral neck dissection, calcitonin decreased, but did not normalise, which requires a large panel of serial imagery assessment to identify the source and provide, if possible, surgical resection $(1,3,4,10)$.

\section{CONCLUSION}

Type 2 MEN Syndrome may embrace various clinical presentations with more or less aggressive tumours, sometimes allowing a long time survival without neoplasia confirmation or incomplete phenotype until advanced age.

Acknowledgement: We thank the patient for her consent of publishing these data.

Conflict of interest: none

\section{REFERENCES}

1. Pappa T., Alevizaki M. Management of hereditary medullary thyroid carcinoma. Endocrine. 2016 Jul; 53(1):7-17.

2. Li Y., Simonds W.F. Endocrine neoplasms in familial syndromes of hyperparathyroidism. Endocr Relat Cancer. 2015 Jun; 23(6):R229-47.
3. Frank-Raue K., Raue F. Hereditary Medullary Thyroid Cancer GenotypePhenotype Correlation. Recent Results Cancer Res. 2015; 204:139-56. doi: 10.1007/978-3-319-22542-5_6.

4. Taïeb D., Kebebew E., Castinetti F. et al. Diagnosis and preoperative imaging of multiple endocrine neoplasia type 2: current status and future directions. Clin Endocrinol (Oxf). 2014 Sep; 81(3):317-28.

5. Baloescu R., Carsote M., Albu S.E., Valea A. Multiple surgeries and long-term endocrine follow-up in a MEN 
2A syndrome. Journal of Surgical Sciences. 2015; 2(4):204-209.

6. Roy M., Chen H., Sippel R.S. Current understanding and management of medullary thyroid cancer. Oncologist. 2013; 18(10):1093-100.

7. Salehian B., Samoa R. RET gene abnormalities and thyroid disease: who should be screened and when. J Clin
Res Pediatr Endocrinol. 2013; 5 Suppl 1:70-8. doi: 10.4274/Jcrpe.870.

8. Poiana C., Chirita C., Carsote M. et al. Pheochromocytoma - from endocrinologist to surgeon. Chirurgia (Bucur). 2009 Nov-Dec; 104(6):753-6

9. Wohllk N., Schweizer H., Erlic Z. et al. Multiple endocrine neoplasia type 2. Best Pract Res Clin Endocrinol Metab. 2010 Jun; 24(3):371-87.

10. Lang B.H., Yu H.W., Lo C.Y. et al. Bilateral Pheochromocytomas in MEN 2A Syndrome: A Two-Institution Experience. World J Surg. 2015 Oct; 39(10):2484-91. 